\title{
A brief review of the use of environmental chambers for gas phase studies of kinetics, chemical mechanisms and characterisation of field instruments
}

\author{
P.W. Seakins \\ School of Chemistry, University of Leeds, Woodhouse Lane, Leeds, LS2 9JT, UK
}

\begin{abstract}
This introductory review considers the role of environmental chambers in atmospheric chemistry, emphasising the importance of being able to carry out studies in controlled conditions. The advantages and disadvantages of different types of chambers are discussed and compared. Examples of the use of chambers for kinetic and mechanistic studies are presented. The final section of this brief review considers the use of chambers in providing a well defined environment for calibrating and investigating the performance of field instruments.
\end{abstract}

\section{Introduction}

Environmental chambers are chemical reactors in which one can simulate aspects of the real atmosphere, but where one has much greater control over both physical conditions (temperature, pressure, light flux) and chemical composition. Environmental chambers have vital roles to play in the determination of rate coefficients, validation of chemical mechanisms and investigation of the characteristics of field instruments.

Our understanding of the chemistry of the Earth's atmosphere is encapsulated in a chemical model, a series of coupled chemical reactions describing the chemical processing of species released into the atmosphere (primary emissions) and of the intermediate compounds formed from these primary emissions. Chemical models can range from near explicit models such as the Master Chemical Mechanism (http: //mcm. leeds.ac.uk/MCM, modelling the degradation of 135 hydrocarbons via several thousand intermediates and $>13,000$ reactions [1]) to more condensed mechanisms such as GEOSCHEM (http: //acmg. seas.harvard.edu/geos/, 280 chemical and photochemical reactions [2]) which can be coupled with transport models. Such models require as inputs the rate coefficients for all reactions; in most cases these will be temperature and in some cases, pressure dependent. Predominantly, atmospheric reactions involve reactions of reactive radical species and there are often more than one set of products for each reaction. Chemical models not only require the overall rate coefficient for the removal of reagents, but the channel specific rate coefficients for each pathway [3].

Figure 1 shows the oxidation pathway of a typical hydrocarbon released into the atmosphere. The initial stage in the oxidation process;

$$
\mathrm{OH}+\mathrm{RH} \rightarrow \mathrm{H}_{2} \mathrm{O}+\mathrm{R}
$$

can usually be studied under isolated conditions as the $\mathrm{OH}$ radical can readily be generated (either by flash photolysis or discharge flow) and $\mathrm{RH}$ can be purchased or synthesised. However, reactions further down the oxidation pathway often involve radicals that are less easy to generate (e.g. alkoxy

This is an Open Access article distributed under the terms of the Creative Commons Attribution-Noncommercial License 3.0, which permits unrestricted use, distribution, and reproduction in any noncommercial medium, provided the original work is properly cited. 


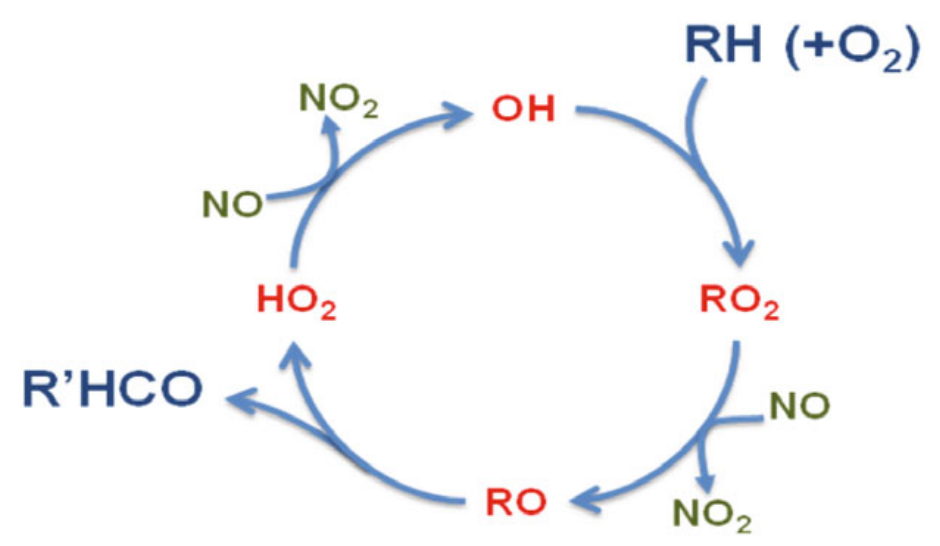

Fig. 1. Oxidation scheme for transformation of an alkane (RH) to a carbonyl (R'HCO).

radicals [4], RO in Fig. 1) or co-products that are not commercially available or easy to synthesise. Under these conditions the reactions need to be studied in environmental chambers where the reagents can be generated in situ and where the physical and chemical conditions have been adjusted to provide measurements with maximum sensitivity to the reaction to be studied. Environmental chambers therefore have an important role in determining rate coefficients and branching ratios.

Once a chemical mechanism has been proposed it needs to be validated against observations. Comparisons with field measurements are not a good way to validate a chemical model as concentrations of most species in the field will be influenced by chemistry and by physical parameters such as local emission rates, long range transport and deposition. Unless these latter parameters are extremely well characterised, the field measurements will not provide unambiguous corroboration of the proposed model. In addition, in many field environments, for example in cities or forests, the chemical complexity is very high, with 10 s or 100 s of different hydrocarbon species being released. Environmental chambers provide a much more controlled environment to validate mechanistic predictions as one has control over the initial starting composition and can focus on the chemistry as opposed to the physical processes.

Whilst field measurements may not always be the most efficient way to unravel a chemical mechanism, they are clearly vital in determining what is present in the atmosphere and the ultimate test of our understanding is whether we can reproduce field measurements. Field studies of the $\mathrm{OH}$ radical are particularly important [5] as $\mathrm{OH}$ determines the chemical lifetime of most atmospheric species and the high reactivity of $\mathrm{OH}$ (the $\mathrm{OH}$ lifetime is usually less than 1 second) means that concentrations are determined by local chemistry rather than by transport. Hence, whilst determining accurate $\mathrm{OH}$ concentrations is a difficult task, such measurements provide vital knowledge and a stringent test of a chemical model. The atmosphere is a challenging environment in which to make measurements. The presence of reactive species such as ozone, humidity and the complexity of the atmosphere mean that instruments can be subject to interferences and other systematic errors. Chambers provide ideal environments in which to calibrate, compare instruments and systematically investigate possible interferences.

In this introductory review we firstly consider the underlying issues behind the designs of different types of chamber (section 2) before going on to describe and contrast different types of chamber in section 3. Section 4 details some of the instrumentation that is commonly used in environmental chambers and finally in section 5, we discuss applications of chambers to kinetics and mechanistic studies and to the calibration and characterisation of field instruments.

\section{Conditions}

Temperatures and pressures in the troposphere vary from $\sim 320-200 \mathrm{~K}$ and $1000-100 \mathrm{mbar}$. Reactive biogenic compounds, such isoprene with a lifetime of $\sim 1 \mathrm{hr}$, react essentially under the ambient 
conditions at their release, but longer lived emissions will sample a much wider range of conditions and aircraft and volcanoes emit directly into the upper regions of the troposphere $(<220 \mathrm{~K}, \sim 100 \mathrm{mbar})$. Therefore, whilst studies at standard temperatures and pressures will provide much useful information, the ideal chamber should operate over the temperatures and pressures relevant to the troposphere.

Solar photochemistry provides the driving force for a majority of daytime chemistry in the atmosphere. The low wavelength cut off of sunlight in the troposphere is $290-310 \mathrm{~nm}$ and few molecules are susceptible to photolysis above $500 \mathrm{~nm}$ (thermodynamically sufficient only to break bonds weaker than $\sim 240 \mathrm{~kJ} \mathrm{~mol}^{-1}$ ). If one is interested in replicating the conditions in the atmosphere then it is best use either solar radiation (e.g. outdoor chambers such as EUPHORE or SAPHIR [6]) or to have light sources that reproduce the solar spectrum as closely as possible. Other studies might require shorter wavelengths to generate utilise particular radical sources or the use of filters to limit the light to narrow wavelength regions.

A significant fraction of atmospheric chemistry occurs on or in aerosol particles. A detailed description of such processes is beyond the remit of this review, but several environmental chambers have been constructed to focus on heterogeneous chemistry [7-9]. These studies can include exploring the mechanisms of particle formation from gas phase species or the growth and evolution of aerosol from existing 'seed particles'. For the latter studies consideration needs to be given to the nature (organic/inorganic) and concentration of such particles [10]. The formation, properties and impact of secondary organic aerosol has recently been reviewed by Hallquist et al. [11].

The discussion of heterogeneous processes leads us to consider the composition of the walls of an environmental chamber. The atmosphere is for the most part a wall-less reactor but clearly environmental chambers must have some physical boundaries. The larger the chamber, the smaller the surface to volume ratio, minimizing the potential effects of wall reactions, however, practical considerations of cost, space and construction material limit the size of reactors. Depending on the size and applications, chambers can be constructed from a variety of materials including Teflon film, glass, quartz or metal.

The final consideration is the concentration of species introduced or generated in the chamber. Ideally chambers should have the capability of operating under concentrations as similar as possible to those in the atmosphere and this may require the use of sensitive detection techniques. Radical species are difficult to detect at ambient levels and there may be other practical reasons why one would want to work at higher radical concentrations. However, under these conditions, care must be taken in scaling up concentrations; increasing radical concentrations will promote radical-radical reactions that may not be significant under ambient conditions, and hence the resultant product distribution will not be representative of the atmosphere. It is usual to run some sort of chemical model to check on the significance of such processes.

A major issue involving composition is the $\mathrm{NOx}\left(\mathrm{NO}+\mathrm{NO}_{2}\right)$ concentration, or more particularly the NOx:VOC ratios (VOC = volatile organic compound). In the atmosphere the concentration of NOx is crucial in determining the mechanism of hydrocarbon oxidation. At relatively high [NOx], the chemistry follows that of Fig. 1. At low NOx levels, $\mathrm{RO}_{2}$ radicals primarily react with other peroxy radicals (section 5.2.1) rather than propagating the chain reaction with NO. The construction of the chamber, the purity of the materials and the mechanisms for $\mathrm{OH}$ generation used influence the chemical regimes that can be studied. Teflon chambers usually have a significant background concentration of NOx and other nitrogen species. For example in the SAPHIR and EUPHORE chambers nitrous acid, HONO, from the walls is often used as the $\mathrm{OH}$ radical source [12]. Other $\mathrm{OH}$ sources include the photolysis of methyl nitrite, $\mathrm{CH}_{3} \mathrm{ONO}$, which indirectly generates $\mathrm{OH}$. Both $\mathrm{HONO}$ and $\mathrm{CH}_{3} \mathrm{ONO}$ photolysis result in the presence of significant NOx. Other $\mathrm{OH}$ sources can be used, such as photolysis of hydrogen peroxide, but these are not without their own problems.

\section{Chamber designs}

\subsection{Outdoor chambers}

One of the most obvious methods of categorising environmental chambers is the division between natural solar - 'outdoor chambers' or artificial irradiation - 'indoor chambers'. The characteristics of 
several outdoor chambers are shown in the first part of Table 1 and two examples are shown in Fig. 2. Outdoor chambers are constructed from Teflon film supported by a metal framework. These chambers are intrinsically fragile, hence need to be surrounded by a retractable weather and light proof structure which protects the chamber and allows 'dark reactions' to be carried out. The major advantages of such chambers are their large size providing a small surface to volume ratio and plenty of space for the installation of sensitive monitoring equipment, for example DOAS detection of $\mathrm{OH}$ (which requires a long base path length, section 4.3.1) in the SAPHIR chamber or FAGE detection (requiring significant gas sampling) of OH in the SAPHIR and EUPHORE chambers [13].

Solar radiation is obviously ideal if the aim is to simulate atmospheric processes but has other drawbacks; the solar flux needs to be monitored as it will vary gradually during the day and more sharply due to clouds. In addition it is impossible to guarantee reproducible irradiation from day to day or to select particular wavelength regions for study.

A major limitation of Teflon chambers is that they are only operable at ambient conditions of temperature and pressure, preventing the systematic study of temperature and pressure dependence which can be of both practical use in modelling the upper troposphere, but may also reveal information on the mechanism of a particular process. Whilst the use of Teflon minimises surface chemistry, it does not altogether remove wall effects. As mentioned above HONO on chamber walls can be used as a photolytic $\mathrm{OH}$ source and the inability to clean the walls or evacuate the chamber limits the base level of NOx which can be reached and hence the NOx : VOC ratio. Teflon chambers cannot be made leak tight and hence the chamber is usually operated at a very slight over pressure to prevent in the ingress of ambient air. Finally, the size of the chambers means that running costs are high and logistical considerations (e.g. provision of a clean air supply and the mixing of reagents) can be significant.

\subsection{Indoor chambers}

All indoor chambers by necessity have artificial light sources. Radiation sources can chosen to simulate the solar spectrum, to focus on the photochemically active regions from 300-400 nm, or deep UV lamps, usually based on mercury emission at $254 \mathrm{~nm}$, can be used to access alternative radical sources. An important objective is to produce as uniform a radiation field as possible across the chamber. With glass, quartz or Teflon chambers this usually means mounting the lamps outside the chamber; for metal chambers there is no alternative but to have internally mounted lamps with resultant 'hot spots' of higher light intensity around the lamps. However, careful design can limit such effects and Fig. 3 shows that in the University of Leeds' HIRAC (Highly Instrumented Reactor for Atmospheric Chemistry [20]) chamber the distribution of radiation is relatively uniform across a majority of the chamber with less than $\pm 10 \%$ variation over $85 \%$ of the chamber volume. Studies should be carried out to investigate whether there are significant spatial inhomogeneities in radical distributions.

Indoor chambers can be constructed from Teflon, glass, quartz or metal. Table 1 also lists the characteristics of some indoor chambers. Indoor Teflon reactors have the same advantages and disadvantages as their outdoor counter parts. Teflon reactors are cheap to construct and can be used to make large reactors such as the $27 \mathrm{~m}^{3}$ PSI chamber [8] or the $28 \mathrm{~m}^{3}$ chamber operated by the Tennessee Valley Authority [26]. Large sized chambers are particularly useful for aerosol studies. Set against these advantages are the disadvantages of being limited to ambient temperatures and pressures and not being able to clean the chambers by pumping, although the chamber can be replaced from time to time at relatively low cost.

Glass, or less commonly quartz, cylindrical reactors are often used. Sizes range from cubic metres [22] to $\sim 100 \mathrm{~L}$ [27]. The larger scale reactors have good surface to volume ratios and their base lengths of $\sim 1-3$ m ensures good path lengths for optical detection techniques such as Fourier transform IR (FTIR) or UV spectrometry. Glass provides a relatively inert surface and many chambers can be evacuated to help facilitate cleaning. The end flanges of most cylindrical glass chambers can be removed to allow occasional manual cleaning. These end flanges, which are usually made of metal, also provide mounts and coupling for optical components and injection and sampling ports.

Metal chambers allow operation of a wide range of temperatures and pressures. Chambers can be heated/cooled by flowing a suitable liquid around the outside of the chamber. In the NCAR chamber 
Table 1. Examples of environmental chambers which focus predominantly on gas phase chemistry.

\begin{tabular}{|c|c|c|c|}
\hline Name & Location & Description & Reference \\
\hline UNC Chamber & $\begin{array}{l}\text { University of North } \\
\text { Carolina, USA }\end{array}$ & $\begin{array}{l}\text { Outdoor. } 2 \times 150 \mathrm{~m}^{3} \text { Teflon film chambers. } \\
\text { Filled with ambient air (rural location). GC } \\
\text { (VOC and OVOC) analysis with supporting } \\
\text { NOx, } \mathrm{CO} \text { and } \mathrm{O}_{3} \text { analysers. }\end{array}$ & [14] \\
\hline CSIRO & Sydney, Australia & $\begin{array}{l}\text { Outdoor. } 2 \times 20 \mathrm{~m}^{3} \text { cubic Teflon film cham- } \\
\text { bers filled with purified air (NOx }<10 \mathrm{ppb} \text { ). } \\
\text { NMHC GC analysis supported by NOx and } \\
\mathrm{O}_{3} \text { analysers. }\end{array}$ & [15] \\
\hline SAPHIR & Julich, Germany & $\begin{array}{l}\text { Outdoor. Cylindrical } 270 \mathrm{~m}^{3} \text { Teflon film } \\
\text { chamber filled with purified air. GC, GC-MS, } \\
\text { HPLC analysis of stable compounds. DOAS } \\
\text { and LIF for radical detection. }\end{array}$ & {$[16,17]$} \\
\hline EUPHORE & Valencia, Spain & $\begin{array}{l}\text { Outdoor. Hemispherical } 200 \mathrm{~m}^{3} \text { Teflon film } \\
\text { filled with purified air. GC, GC-MS for VOC, } \\
\text { long path FTIR and FTUV, LIF for radical de- } \\
\text { tection, LOPAP for HONO monitoring. }\end{array}$ & [17] \\
\hline EXACT & Manchester, UK & $\begin{array}{l}\text { Indoor. Small } 123 \text { litre Teflon lined, cylindri- } \\
\text { cal chamber designed to probe a wide range of } \\
\text { temperatures and pressures. }\end{array}$ & [18] \\
\hline NCAR chamber & Boulder, USA & $\begin{array}{l}\text { Indoor. Small } \sim 50 \text { litre stainless steel cham- } \\
\text { ber. UV lamp mounted end on. FTIR detec- } \\
\text { tion of products. Wide temperature variation } \\
\text { possible. }\end{array}$ & [19] \\
\hline \multirow[t]{4}{*}{ HIRAC } & Leeds, UK & $\begin{array}{l}\text { Indoor. } 2 \mathrm{~m}^{3} \text { cylindrical stainless steel cham- } \\
\text { ber. Temperature and pressure variable. FTIR, } \\
\text { GC and analysers for stable product analysis. } \\
\text { FAGE and CRDS for radical detection. }\end{array}$ & {$[20,21]$} \\
\hline & $\begin{array}{l}\text { Wuppertal, } \\
\text { Germany }\end{array}$ & $\begin{array}{l}\text { Indoor. Several cylindrical chambers ranging } \\
\text { from } 350-1000 \text { litres, with glass or quartz } \\
\text { construction (metal end flanges). FTIR, GC, } \\
\text { GC-MS detection of VOC, analysers for NOx } \\
\text { and } \mathrm{O}_{3} \text {. HONO detection. }\end{array}$ & {$[17,22,23]$} \\
\hline & $\begin{array}{l}\text { University of } \\
\text { California, } \\
\text { Riverside, USA }\end{array}$ & $\begin{array}{l}\text { Indoor. } 2 \times 90 \mathrm{~m}^{3} \text { cubical Teflon film cham- } \\
\text { ber, illuminated by argon arc lamp or black } \\
\text { lamps. Standard analysers and GC facilities, } \\
\text { plus tuneable diode laser spectroscopy and } \\
\text { aerosol characterisation. }\end{array}$ & [9] \\
\hline & $\begin{array}{l}\text { National Institute for } \\
\text { Environmental Stud- } \\
\text { ies, Japan }\end{array}$ & $\begin{array}{l}\text { Indoor. Cylindrical Teflon lined stainless steel } \\
\text { chamber of } 6 \mathrm{~m}^{3} \text { illuminated by solar sim- } \\
\text { ulator. Analyses by commercial analysers } \\
\left(\mathrm{NOx}, \mathrm{O}_{3}\right) \text { and long path FTIR. }\end{array}$ & [24] \\
\hline CRAC1 & $\begin{array}{l}\text { University of Cork, } \\
\text { Eire }\end{array}$ & $\begin{array}{l}\text { Indoor. Cylindrical } 4 \mathrm{~m}^{3} \text { Teflon film chamber. } \\
\text { TUV or UV lamps. FTIR and GC analysis. } \\
\text { Instruments for aerosol characterisation and } \\
\text { analysis. }\end{array}$ & [25] \\
\hline
\end{tabular}

(47 L) the liquid flows through a jacket surrounding the chamber [19]. This jacket is in turn surrounded by an evacuated chamber to provide insulation. This effective insulation and the relatively smaller size of the chamber allows for a wide range of temperatures $(215-470 \mathrm{~K})$ and rapid temperature equiliberation. In the larger, $2 \mathrm{~m}^{3}$, HIRAC chamber [20] the heated/cooled thermofluid passes along channels that have been wielded to the sides of the chamber and the whole chamber is then covered in neoprene insulation. HIRAC has been cooled to $225 \mathrm{~K}$. 


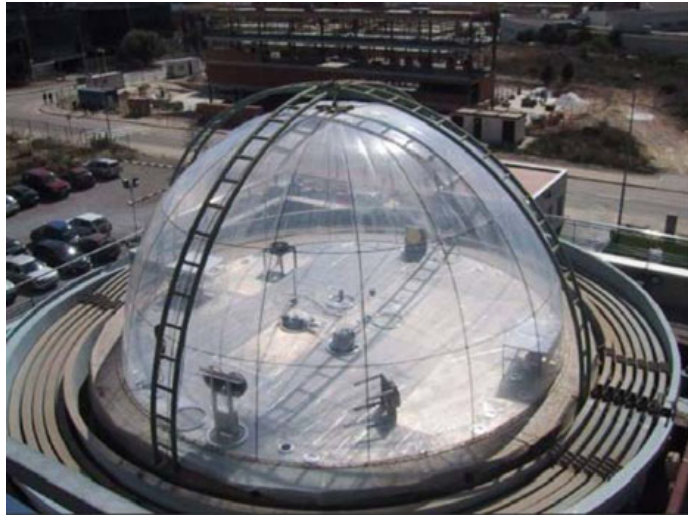

(a)

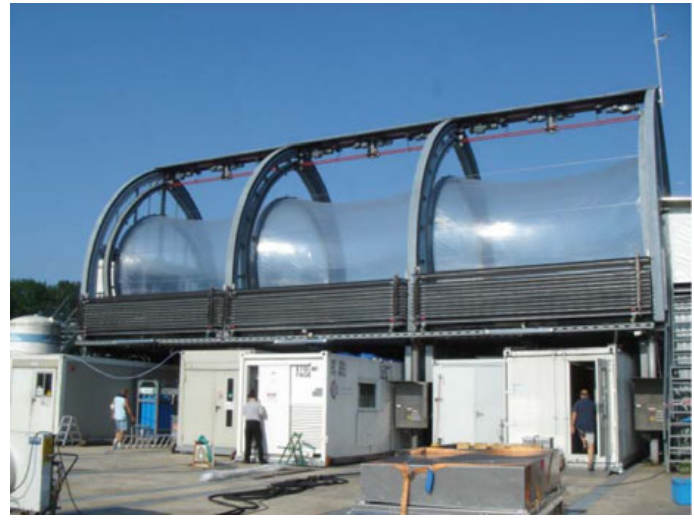

(b)

Fig. 2. (a) The EUPHORE chamber in Valencia. (b) The SAPHIR chamber in Julich.

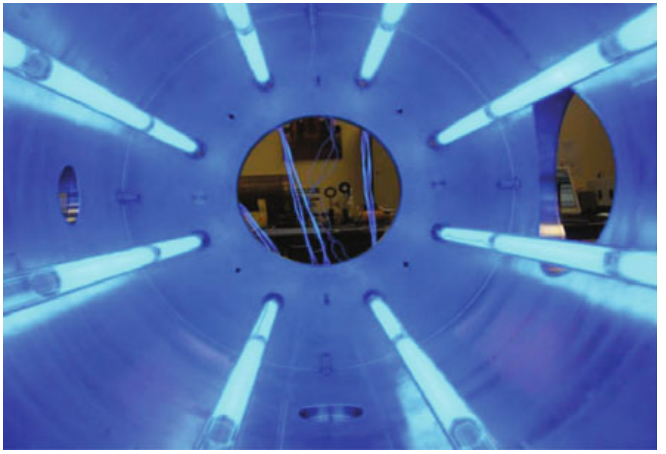

(a)

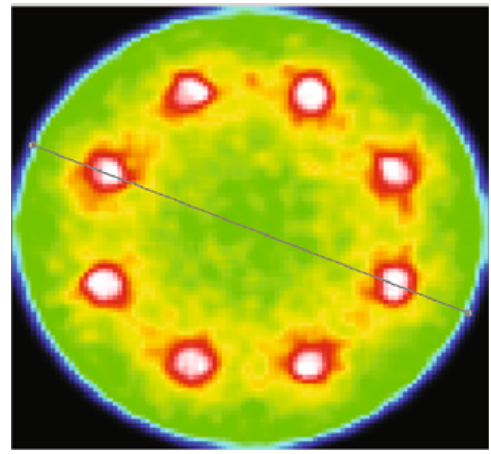

(b)

Fig. 3. (a) Lamps inside the HIRAC chamber. (b) Calculated radiation distribution across the HIRAC chamber.

As with glass chambers, metal chambers are generally cylindrical in design; metal construction allows for a wide variety of flanges and connectors to be flexibly mounted onto the chamber and not just into the end flanges (see section 4.3.1 on OH detection by FAGE). Chambers are constructed out of stainless steel or aluminium and under normal operating conditions wall loss rates appear to be minimal. Both stainless steel and aluminium have been used in the construction of the end flanges of various glass chambers. The ability to evacuate and also to heat the walls of the chamber facilitates cleaning of the chamber. As mentioned above, the major disadvantage is the non-uniform light distribution in the chamber.

Each design of chamber, whether indoor/outdoor, metal, Teflon or glass, has its own advantages and disadvantages, there is no one perfect design. It is important to be aware of these characteristics and to design experiments to play to the strengths of the particular chamber.

\section{Measurement techniques}

\subsection{Monitoring physical parameters}

Measurement of temperature and pressure is straight forward but important. Thermocouples are generally used for temperature measurement and a variety of commercial pressure measurement devices are available. Cooling or heating a large chamber is a non-trivial with potential for significant temperature gradients without good design of the circulating system or efficient internal mixing. Temperature 
profiles taken across the HIRAC chamber at a nominal temperature of $225 \mathrm{~K}$, show variations of $\pm 2 \mathrm{~K}$. Pressures can be measured with a wide variety of commercial devices.

The other important physical parameter to determine is the light distribution within the chamber. This can be done relatively simply, for example using a photodiode, to measure the total intensity. It is important to recognise that reflected light may contribute significantly to the light intensity at any point in the chamber. Spectral radiometers are more sophisticated measurement devices which provide a measure of the wavelength resolved intensity of light; such measurements can be particularly useful in outdoor chambers $[14,28]$.

\subsection{Monitoring stable gas phase species}

A wide variety of techniques can be used to monitor stable gas phase species such as hydrocarbons, $\mathrm{NOx}, \mathrm{CO}, \mathrm{CO}_{2}$, water and ozone. In this section we will focus on three types of measurement techniques: optical spectroscopy, chromatography and commercial analysers. Many compounds can be, and are, detected by more than one technique which can help identify systematic errors in measurements.

\subsubsection{Optical spectroscopy}

Fourier transform IR (FTIR) spectroscopy is probably the most common detection method used in chambers around the world. Virtually every compound has a unique IR spectrum associated with vibrations so the technique is widely applicable. Compound identification is based on spectral assignments either of literature spectra (e.g. NIST Chemistry WebBook http://webbook.nist.gov/chemistry/) or ideally from calibration spectra recorded directly in the chamber at the same resolution as the experiments. Many peaks will overlap and hence identification of minor products can require sophisticated analysis, stripping out the more dominant reagent or product spectra. Once peaks have been uniquely assigned to a particular compound, then peak height (or area) can be used to quantify the concentration of the species based on the Beer Lambert law:

$$
I_{t}=I_{0} e^{-\sigma c l}
$$

where $I_{t}$ and $I_{0}$ are the transmitted and incident IR intensities at a particular wavelength, $\sigma$ is the IR absorption crossection at that wavelength, $c$ is the concentration and $l$ is the pathlength.

It can be seen from the Beer Lambert law that the detection limit for a given species depends on its absorption cross section and also on the path length over which absorption occurs. In most chambers the IR radiation is multipassed within the chamber using high reflectivity mirrors arranged in the White optics [29] configuration or modifications such as the Chernin configuration [30,31], in order to extend the path length. The number of passes is a trade off between the increased path length and the loss of overall intensity at each reflection. Typical path lengths are over a hundred metres for an indoor chamber with a $2 \mathrm{~m}$ base length and may be considerably more for larger outdoor chambers. Detection limits are typically 10's of parts per billion ( $\mathrm{ppb}$ ) for common species.

Spectra can be run at a variety of resolutions, a $1 \mathrm{~cm}^{-1}$ spectrum is sufficient to resolve rotational structure for most diatomic molecules. Rotational resolution of polyatomic species requires resolutions beyond that of most commercial instruments. In FT spectroscopy resolution is inversely proportional to the acquisition time so that the collection time of very high resolution spectra is also prohibitively long. Most modern commercial FTIR spectrometers have facilities for recording rapid spectra at low resolution, typically $16 \mathrm{scans} \mathrm{s}^{-1}$ at $\sim 10 \mathrm{~cm}^{-1}$ resolution, so that rapid changes in concentrations can be observed.

UV and visible absorption methods are also applied to chamber studies, however, many species have unstructured UV/vis spectra making compound identification and quantification difficult. There are significant exceptions, for example glyoxal, $(\mathrm{HCO})_{2}$, an important intermediate in aromatic oxidation [32], has a very structured and strong UV spectrum, allowing selective and sensitive detection. 
Table 2. Review of selected commercial analysers.

\begin{tabular}{|l|l|l|}
\hline Species & \multicolumn{1}{|c|}{ Method/Detection Limit } & \multicolumn{1}{c|}{ Comments } \\
\hline $\mathrm{O}_{3}$ & UV absorption/1ppb & $\begin{array}{l}\text { Possible interferences, can be compared with } \\
\text { FTIR (which has a higher detection limit) }\end{array}$ \\
\hline $\mathrm{NO}$ & $\begin{array}{l}\text { Chemiluminescence - NO reacts with } \\
\text { excess } \mathrm{O}_{3} \text { which generates electronically ex- } \\
\text { cited } \mathrm{NO}_{2} \text {. Fluorescence from } \mathrm{NO}_{2} \text { is propor- } \\
\text { tional to the NO concentration. Standard instru- } \\
\text { ments have detection } \\
\text { limits around 1 ppb, for trace level instruments } \\
\text { this can be reduced to 50 pptv }\end{array}$ & $\begin{array}{l}\text { Fluorescence techniques require } \\
\text { calibration. }\end{array}$ \\
\hline $\mathrm{NO}_{2}$ & $\begin{array}{l}\text { Indirect chemiluminescence }-\mathrm{NO}_{2} \text { in the sam- } \\
\text { ple is reduced to NO and then the total NO is } \\
\text { detected as above. }\end{array}$ & $\begin{array}{l}\text { Potential interferences from other nitrogen } \\
\text { oxide species which may also be } \\
\text { reduced to NO. }\end{array}$ \\
\hline $\mathrm{CO}_{2} \mathrm{CO}_{2}$ & IR absorption/ & \multicolumn{2}{|l|}{} \\
\hline Water & IR absorption or dew point hydrometer & \\
\hline
\end{tabular}

\subsubsection{Chromatographic techniques}

During a mechanistic study a large range of primary, secondary and tertiary products will be produced. Overlapping IR peaks may prevent analysis by FTIR and under these conditions the separating power of chromatography becomes important. In contrast to in situ FTIR observation, chromatography requires that a sample is taken from the chamber. There are a variety of ways in which this can be achieved, but in all cases one must be aware that the analyte might be lost or degraded during the sampling process.

We will focus in this section on the most common technique, gas chromatography, but other forms of chromatography such as HPLC have been used. Sampling techniques used include coupling the chamber to the GC with a gas sampling valve to provide on line, automated sampling, direct sampling and injection with a gas syringe, whole air sampling with evacuated canisters or preconcentration by trapping the air sample on a solid sorbent bed followed by thermal desorption onto the GC.

Gas chromatography can be coupled to a variety of detectors for sample quantification and in some cases identification. The simplest detector is a flame ionization detector (FID), a very cost effective, robust and sensitive detection for most hydrocarbon species. FID provides no compound identification and hence compounds must be identified by their characteristic retention time in the column as determined by the injection of pure samples. Quantification requires the construction of calibration plots. Electron capture (ECD) and helium ionization (HID) detectors are other examples of detectors which provide enhanced sensitivity for the detection of electronegative species (ECD) or compounds which do not burn (HID). Compound identification requires the use of mass spectrometry (MS) and a number of chambers use commercial GC-MS systems.

Mass spectrometry can also be used directly in compound identification and quantification. Both chemical ionization mass spectrometry (CIMS) [33] and proton transfer mass spectrometry (PTR MS) [34] have been successfully used in chamber studies [35].

\subsubsection{Commercial analysers}

A number of different commercial analysers are available to monitor common species such as ozone, $\mathrm{NOx}, \mathrm{CO}, \mathrm{CO}_{2}$ and water and these are briefly described in Table 2.

\subsection{Monitoring gas phase radical species}

The majority of atmospheric chemistry is driven by radical reactions and important radical species include $\mathrm{HOx}\left(\mathrm{OH}\right.$ and $\left.\mathrm{HO}_{2}\right), \mathrm{RO}_{2}$ and $\mathrm{NO}_{3}$. Techniques for monitoring these species are described below. 


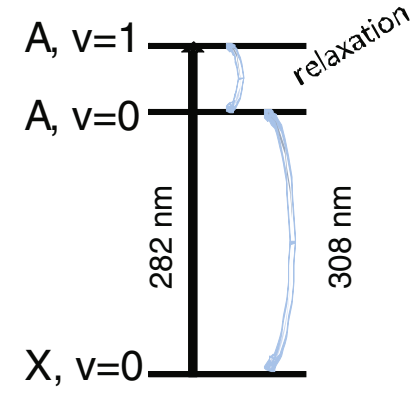

(i)

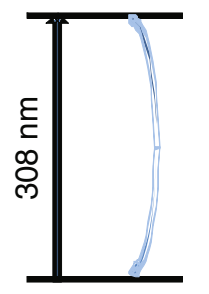

(ii)

(a)

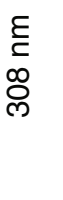

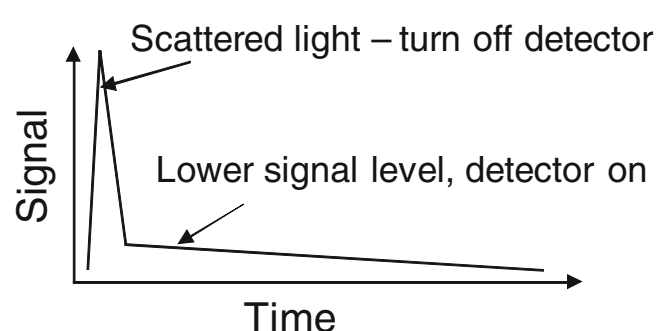

(b)

Fig. 4. (a) Laser induced fluorescence schemes. (b) Temporal discrimination against scattered light.

\subsubsection{HOx detection}

Chamber measurements of $\mathrm{OH}$ have primarily involved the use of the FAGE (fluorescence assay by gaseous expansion) technique in outdoor chambers, although FAGE has also been implemented in the indoor HIRAC chamber [20] and DOAS (differential optical absorption spectroscopy) has been used in the SAPHIR chamber [36].

FAGE [37] is based on laser induced fluorescence on the $\mathrm{A} \leftarrow \mathrm{X}$ electronic states; early laser induced fluorescence techniques excited $\mathrm{OH}$ to the first vibrational level of the A state (282 nm light), observing fluorescence at $308 \mathrm{~nm}$ (Figure 4(a) (i)) through an optical filter to remove scattered laser light, however ozone photolysis by the $282 \mathrm{~nm}$ light, in the presence of water, yielded spurious $\mathrm{OH}$ signals (the technique is still used successfully in upper atmosphere studies where water vapour concentrations are low). Excitation to the ground vibrational state $(308 \mathrm{~nm})$ stops the production of instrumental $\mathrm{OH}$, but the weak fluorescence signal, also at $308 \mathrm{~nm}$ (Figure 4(a) (ii)) is swamped by scattered probe light. However, as pressure is reduced the lifetime of the fluorescence is increased allowing the photomultiplier detector to be electronically gated, i.e. turned off for the laser pulse and scatter and then turned on to detect fluorescence (Figure 4(b)). Air from the chamber is drawn into the FAGE apparatus through a $\sim 1 \mathrm{~mm}$ diameter pinhole into a low pressure (2-4 Torr) chamber where it is interrogated by a pulse of $308 \mathrm{~nm}$ light. Fluorescence is observed perpendicularly to the incoming probe laser.

The same technique can be used to probe for $\mathrm{HO}_{2}$ radicals by chemically titrating $\mathrm{HO}_{2}$ to $\mathrm{OH}$ by the addition of NO:

$$
\mathrm{HO}_{2}+\mathrm{NO} \rightarrow \mathrm{OH}+\mathrm{NO}_{2}
$$

$\mathrm{NO}$ is injected into the gas flow downstream of the first $(\mathrm{OH})$ fluorescence chamber and the additional $\mathrm{OH}$ detected in the second chamber corresponds to the $\mathrm{HO}_{2}$ concentration.

FAGE, as with all fluorescence techniques, is not an absolute method and the system needs to be calibrated by generating known concentrations of $\mathrm{OH}$ and $\mathrm{HO}_{2}$, for example by the photolysis of a water/air mix by a mercury lamp at $185 \mathrm{~nm}$ :

$$
\begin{gathered}
\mathrm{H}_{2} \mathrm{O}+\mathrm{h} v \rightarrow \mathrm{OH}+\mathrm{H} \\
\mathrm{H}+\mathrm{O}_{2} \rightarrow \mathrm{HO}_{2} .
\end{gathered}
$$

DOAS [38] is based on the Beer Lambert law (E1); although less sensitive than fluorescence, absorption has the advantage, that if the absorption cross section is known, then absolute concentrations can be measured without the need for calibrations. DOAS detection of $\mathrm{OH}$ also uses the $\mathrm{A} \leftarrow \mathrm{X}$ transition around $308 \mathrm{~nm}$ [36]. Other species will absorb in this region, the intensity of the absorption 


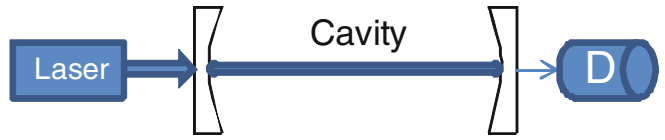

(a)

Fig. 5. (a) Schematic of CRDS apparatus. (b) Ring down signal in the absence (upper curve) and presence (lower curve) of an absorbing species.

is measured as a function of wavelength and the sharply structured $\mathrm{OH}$ transition can be separated from both the continuum background and from any other structured spectra. Further issues around $\mathrm{OH}$ calibration and intercomparison are discussed in section 5.3.

$\mathrm{OH}$ is primarily generated by photochemical processes and so concentrations will be influenced by the local light field. DOAS will return an integrated $\mathrm{OH}$ concentration averaged over the beam path length. FAGE is a point measurement. In the HIRAC chamber the sampling position can be moved across the radius of the chamber to investigate spatial dependence associated with a variable light field or wall loss.

\subsection{2 $\mathrm{NO}_{3}$ detection by cavity ring down spectroscopy (CRDS)}

The nitrate radical, $\mathrm{NO}_{3}$, is rapidly photolysed during the day, but at night it can build up in appreciate concentrations and can play a significant role in the oxidation of alkenes and in the production of potentially toxic nitrogen containing compounds.

In CRDS [39,40] a pulse of light is injected into a chamber formed by two highly reflective mirrors. The light bounces back and forth and at each mirror a small percentage is lost; the light transmitted through one mirror is monitored (Fig. 5(a)). In an empty cavity this signal will decay exponentially ('ring down'), as the light leaks out of the cavity, with a time constant that is characteristic of the mirrors and the cavity length (Fig. 5(b)). In the presence of an absorbing species, the ring down time will be significantly shorter as light is lost both by absorption and transmission through the mirrors. The concentration of the absorbing species, $[\mathrm{A}]$, can be related to the difference in ring down times via:

$$
[\mathrm{A}]=\frac{1}{\sigma c}\left(\frac{1}{\tau}-\frac{1}{\tau_{0}}\right)
$$

where $\sigma$ is the absorption crossection of the species A, $c$ is the velocity of light, $\tau$ and $\tau_{0}$ are the ring down times in the presence and absence of the absorber.

CRDS has been used in a wide variety of kinetics applications and in field measurements (see reviews by Wheeler et al. [40] and Brown [41]) and has recently been applied to the HIRAC chamber [21]. CRDS can be applied to the detection of a range of stable and radical species. Other cavity enhanced absorption techniques have been applied to field and chamber measurements [42].

\subsection{3 $\mathrm{RO}_{2}$ detection via PERCA (peroxy radical chemical amplification) detection}

Figure 1 shows that the reaction of $\mathrm{OH}$ with a hydrocarbon will lead to the production of a peroxy $\left(\mathrm{RO}_{2}\right)$ radical. Subsequent $\mathrm{RO}_{2}$ chemistry depends on the NOx concentration. In urban environments where $\mathrm{NO}$ is high, $\mathrm{RO}_{2}$ is rapidly converted to an alkoxy, $\mathrm{RO}$ radical, which goes onto form a carbonyl compound $+\mathrm{HO}_{2}$ with the $\mathrm{HO}_{2}$ being recycled back to $\mathrm{OH}$ via reaction R2. However, in remote 
environments with low NOx, $\mathrm{RO}_{2}$ chemistry is dominated by reaction with $\mathrm{HO}_{2}$ or other $\mathrm{RO}_{2}$ radicals. When $\mathrm{R}$ is an alkyl radical, then the reaction of $\mathrm{RO}_{2}$ and $\mathrm{HO}_{2}$ leads to the formation of soluble peroxide species with no radical regeneration and hence the net loss of ozone as $\mathrm{OH}$ was formed from $\mathrm{O}_{3}$ photolysis. $\mathrm{RO}_{2}$ radicals play an important role in atmospheric chemistry and their direct detection is important.

Figure 1 also emphasises the chain nature of hydrocarbon oxidation in the presence of sufficient 'fuel' (hydrocarbon or CO) and NO. Each time the cycle is completed one or two NO molecules are oxidized to $\mathrm{NO}_{2}$. In the PERCA technique [43] air samples containing $\mathrm{OH}, \mathrm{HO}_{2}$ and $\mathrm{RO}_{2}$ are drawn into the apparatus and react with excess $\mathrm{CO}$ and $\mathrm{NO}$ taking part in a chain reaction:

$$
\begin{gathered}
\mathrm{RO}_{2}+\mathrm{NO} \rightarrow \mathrm{RO}+\mathrm{NO}_{2} \\
\mathrm{RO}+\mathrm{O}_{2} \rightarrow \mathrm{HO}_{2}+\text { carbonyl } \\
\mathrm{HO}_{2}+\mathrm{NO} \rightarrow \mathrm{OH}+\mathrm{NO}_{2} \\
\mathrm{OH}+\mathrm{CO} \rightarrow \mathrm{H}+\mathrm{CO}_{2} \\
\mathrm{H}+\mathrm{O}_{2} \rightarrow \mathrm{HO}_{2}
\end{gathered}
$$

$\mathrm{RO}_{2}$ is converted to $\mathrm{HO}_{2}$ and subsequently $\mathrm{HO}_{2}$ and $\mathrm{OH}$ are interconverted by reactions $\mathrm{R} 2,4$ and 7. Conditions are set such that termination reactions (e.g. $\mathrm{OH}+\mathrm{NO} \rightarrow \mathrm{HONO}$ ) are minimised and chain lengths can reach $10^{3}$ generating readily detectable concentrations of $\mathrm{NO}_{2}$. Background runs, where $\mathrm{CO}$ is replaced by $\mathrm{N}_{2}$ are run to account for $\mathrm{NO}_{2}$ already in the sampled air. The major disadvantages of the PERCA technique are that it is unable to distinguish between $\mathrm{HO}_{2}$ and $\mathrm{RO}_{2}$ and that different $\mathrm{RO}_{2}$ will have differing chain lengths. Regular calibrations are required.

\section{Applications}

We conclude this brief review with some examples of kinetic and mechanistic studies and an example where chambers can be used to help characterise field instrumentation. Clearly there are hundreds of different examples that could be chosen, including the role of chambers in aerosol studies, an important topic in its own right; the examples chosen illustrate the variety of ways in which chambers can be used.

\subsection{Kinetic studies}

Two examples are considered: firstly the reaction of $\mathrm{Cl}$ atoms with ethene, a pressure dependent reaction and secondly ozone alkene kinetics, reactions which are strongly temperature dependent and which generate hydroxyl radicals.

$$
\text { 5.1.1 } \mathrm{Cl}+\mathrm{C}_{2} \mathrm{H}_{4}+\mathrm{M} \rightarrow \mathrm{C}_{2} \mathrm{H}_{4} \mathrm{Cl}+\mathrm{M}
$$

The rate coefficient for the reaction of $\mathrm{Cl}$ atoms with ethene is pressure dependent. The addition of $\mathrm{Cl}$ atoms to the double bond results in the formation of a new bond in an exothermic reaction. The reaction exothermicity initially resides in the newly formed molecule, $\mathrm{C}_{2} \mathrm{H}_{4} \mathrm{Cl}^{*}$, as vibrational energy and unless this energy can be removed by collisions with a bath gas, $\mathrm{M}$, to form stable $\mathrm{C}_{2} \mathrm{H}_{4} \mathrm{Cl}$, the molecule will redissociate.

$$
\mathrm{Cl}+\mathrm{C}_{2} \mathrm{H}_{4} \leftrightarrow \mathrm{C}_{2} \mathrm{H}_{4} \mathrm{Cl}^{*} \stackrel{\mathrm{M}}{\rightarrow} \mathrm{C}_{2} \mathrm{H}_{4} \mathrm{Cl}
$$

At high pressures the rate determining step (rds) is $\mathrm{C}_{2} \mathrm{H}_{4} \mathrm{Cl}$ formation, so the rate coefficient is independent of $[\mathrm{M}]$ and at low temperatures the rds is the removal of energy from the newly formed molecule so the rate coefficient depends linearly with $[\mathrm{M}]$ and hence pressure. These two extreme regions are linked by a 'fall off' curve with intermediate dependence on pressure as shown in Fig. 6 [21]. 


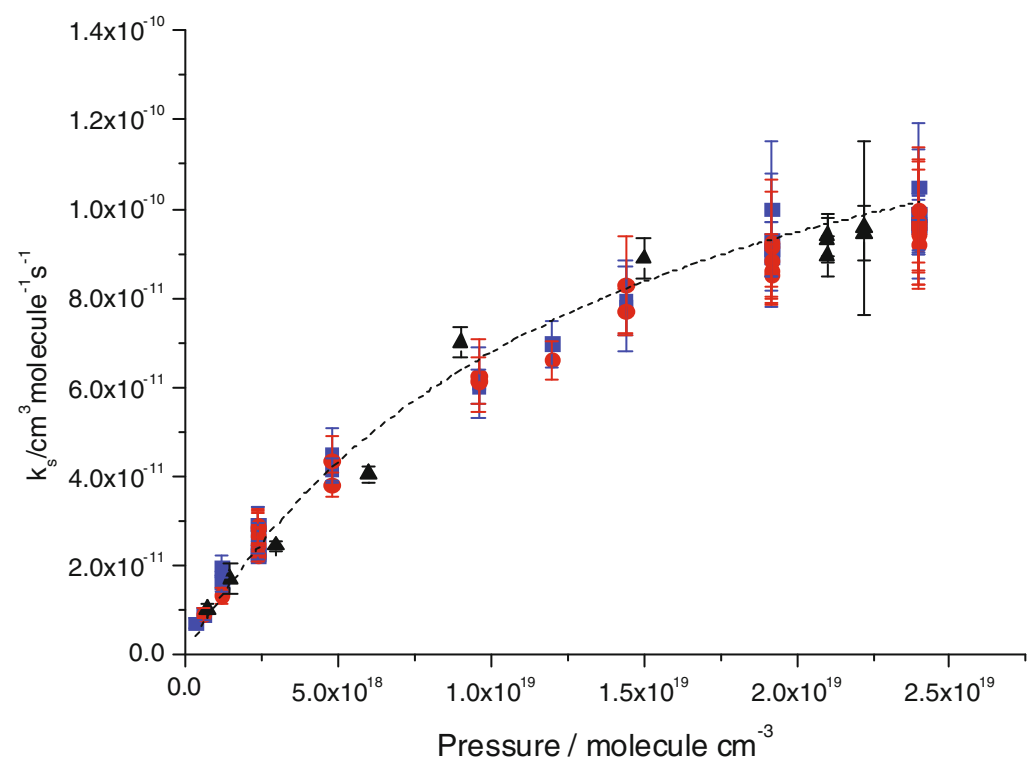

Fig. 6. Fall-off curve showing the rate of loss of $\mathrm{Cl}+$ ethene as a function of total pressure $\mathrm{N}_{2}$. $\boldsymbol{a}$ and $\bullet$ represent the data obtained from relative rate with detection by FTIR and GC, respectively, and the corresponding Troe fit to these data. $\Delta$ represents the data of Wallington et al., [45].

Reaction R8 has been studied by direct time resolved methods by observing the decay of $\mathrm{Cl}$ atoms in the presence of excess ethene, but such studies are costly. Iwasaki et al. [44] have produced an elegant study where reaction R8 has been studied by direct techniques and the results are in good agreement with the much simpler relative rate method. In a relative rate method a pair of hydrocarbons (the test reagent, $\mathrm{SH}$, and a reference compound, $\mathrm{RH}$ ) are reacted with the radical species, $\mathrm{X}$. Concentrations of the hydrocarbons can be monitored by either FTIR or GC techniques. The rate laws for $\mathrm{SH}$ and $\mathrm{RH}$ are given by:

$$
\frac{d[\mathrm{RH}]}{d t}=k_{\mathrm{RH}}[\mathrm{X}][\mathrm{RH}] \text { and } \frac{d[\mathrm{SH}]}{d t}=k_{\mathrm{SH}}[\mathrm{X}][\mathrm{SH}] .
$$

Equations 3(a) and (b) can be combined and integrated to give:

$$
\ln \left(\frac{[\mathrm{SH}]_{\mathrm{t}}}{[\mathrm{SH}]_{0}}\right)=\frac{k_{\mathrm{SH}}}{k_{\mathrm{RH}}} \ln \left(\frac{[\mathrm{RH}]_{\mathrm{t}}}{[\mathrm{RH}]_{0}}\right) .
$$

An example of such a plot is shown in Fig. 7 from a study of reaction R8 [21]. The gradient of the plot yields the ratio of the rate coefficients and as long as $k_{\mathrm{RH}}$ is known, the rate coefficient for the reaction of the radical species can be precisely determined.

The reaction has been studied by monitoring hydrocarbons by both GC and FTIR with the production of consistent rate coefficient ratios suggesting the absence of any systematic measurement errors. Studies using different reference compounds and $\mathrm{Cl}$ atom precursors $\left(\mathrm{Cl}_{2}\right.$ and $\left.(\mathrm{COCl})_{2}\right)$ were carried out to check for other sources of systematic error. The good agreement with all studies including the direct measurements of Iwasaki et al. suggests that this reaction is well characterised. The precise nature of the relative rate experiments produces well defined fall off curves which can be used to test theories of termolecular reactions.

\subsubsection{Ozone + alkene reactions}

Ozone reacts relatively rapidly with alkenes, although the bimolecular rate coefficient is much lower than that for $\mathrm{OH}$ reactions, the significantly higher atmospheric concentrations of $\mathrm{O}_{3}$ compared to $\mathrm{OH}$, 


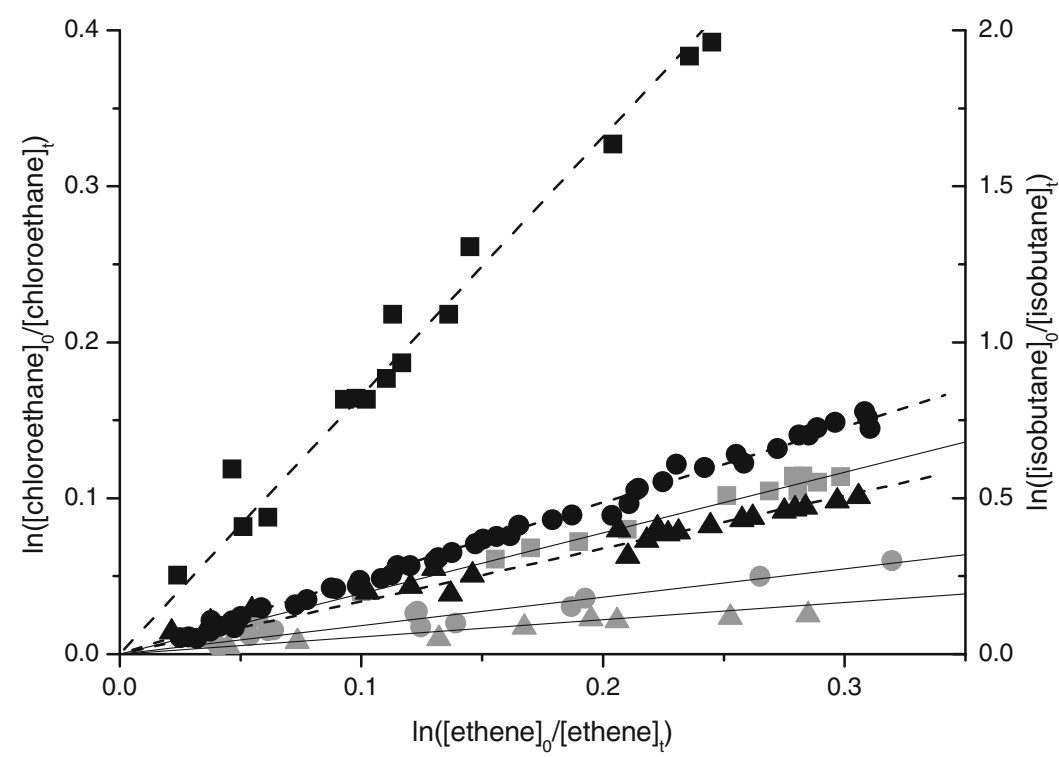

Fig. 7. Plots of $\ln \left([\text { reference }]_{0} /[\text { reference }]_{t}\right)$ versus $\ln \left([\text { ethene }]_{0} /[\text { ethene }]_{t}\right)$ obtained with FTIR. Dashed lines with black symbols, and solid lines with gray symbols indicate measurements using isobutane and chloroethane as the reference, respectively. Triangles, circles, and squares correspond to measurements at 1000, 400, and $100 \mathrm{mbar}$, respectively.

means that ozonolysis reactions are competitive in oxidizing alkenes. The timescales of the chemistry are such that absolute rate studies can be carried out with either $\mathrm{O}_{3}$ or alkene in excess. For example when the alkene is in excess (say [alkene $]_{0}=100^{*}\left[\mathrm{O}_{3}\right]$ ) then the rate law for ozone consumption:

$$
-\frac{d\left[\mathrm{O}_{3}\right]}{d t}=k_{b i}[\text { alkene }]\left[\mathrm{O}_{3}\right]
$$

can be simplified to:

$$
-\frac{d\left[\mathrm{O}_{3}\right]}{d t}=k^{\prime}\left[\mathrm{O}_{3}\right]
$$

where $k^{\prime}$ is the pseudo-first-order rate coefficient and is equal to $k_{b i}$ [alkene].

Leather et al. [18] have used their new EXACT (Extreme Range Chamber), a $123 \mathrm{~L}$ cylindrical, Tefon coated stainless steel reactor to study the reactions of $\mathrm{O}_{3}$ with several $\mathrm{C}_{6}-\mathrm{C}_{8}$ alkenes from 218$336 \mathrm{~K}$. Figure 8 shows the excellent linearities of the (a) first-order plot $\left(\ln \left[\mathrm{O}_{3}\right]\right.$ vs time) to yield $k^{\prime}$ and (b) second-order plot ( $k^{\prime}$ vs [alkene]) to yield the bimolecular rate coefficients. Over the temperature range studied the reactions conform to Arrhenius behaviour (Figure 8(c)).

The results have been interpreted via structure activity relationships which can be used to predict activation energies.

The reaction can also be studied here by observing the decay of alkene in excess ozone, however here care must be taken as ozonolysis leads to the production of $\mathrm{OH}$ radicals [46]. Indeed such kinetic studies can be used to determine the yield of $\mathrm{OH}$ as described below. If the $\mathrm{OH}$ product is scavenged by compounds such as cyclohexane or $\mathrm{CO}$, which do not react with ozone then:

$$
-\frac{d[\text { alkene }]}{d t}=k^{\prime}[\text { alkene }]
$$

where now $k^{\prime}=k_{b i}\left[\mathrm{O}_{3}\right]$ and the alkene is only removed by reaction with ozone. Monitoring the concentration of alkene (e.g. by GC or FTIR) once again yields the bimolecular rate coefficient, but, in experiments where the scavenger is removed, the alkene decays due to removal by both $\mathrm{O}_{3}$ and $\mathrm{OH}$. This enhanced removal of alkene can be used to determine the $\mathrm{OH}$ yield from the ozonolysis reaction. Examples of such studies for the reaction of $\mathrm{O}_{3}$ with isoprene have been carried out in small 


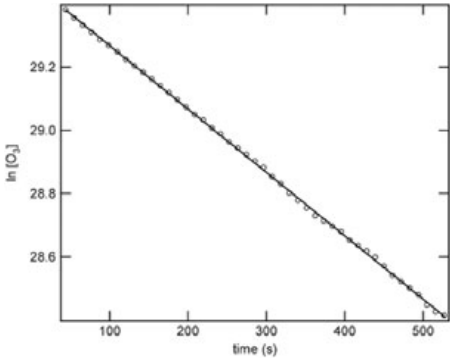

(a)

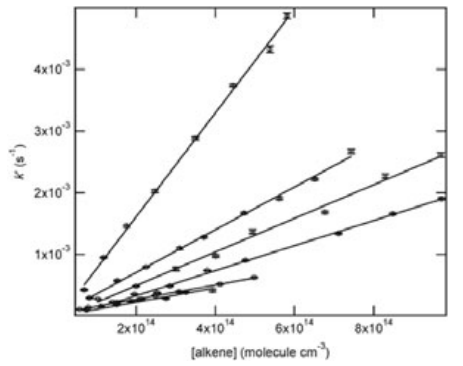

(b)

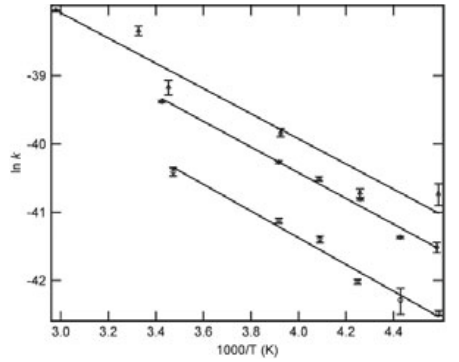

(c)

Fig. 8. (a) First order plot of $\ln \left[\mathrm{O}_{3}\right]$ vs time for the reaction of $\mathrm{O}_{3}$ with 4-methyl-1-pentene. (b) Second plots for 4-methyl-1-pentene from 218-292 K. (c) Arrhenius plots for (from top) 2,4,4-trimethyl-pentene, 4-methyl-1pentene and 3,3-dimethyl-1-butene.

chambers by Neeb and Moortgat [47], Karl et al. [48] in the SAPHIR chamber and Malkin et al. [49] in the HIRAC chamber. Malkin et al. also used the FAGE technique to directly observe the OH produced in the reaction. The $\mathrm{OH}$ yield from this important reaction has been determined as $(0.27 \pm 0.02)$ $[47,49,50]$.

\subsection{Mechanistic studies}

As topical examples of mechanistic studies we will look at two experiments which have shown up new and unexpected $\mathrm{OH}$ production channels from radical-radical reactions. Recent field campaigns in forested tropical regions where NOx levels are low, have indicated significant gaps in our understanding of isoprene, $\mathrm{CH}_{2}=\mathrm{C}\left(\mathrm{CH}_{3}\right) \mathrm{CH}=\mathrm{CH}_{2}$, oxidation chemistry [51] [52]. As discussed in section 4.3.3, hydrocarbon oxidation is the absence of $\mathrm{NO}$ results in the loss of radical species due to $\mathrm{RO}_{2}+\mathrm{RO}_{2}$ or $\mathrm{RO}_{2}+\mathrm{HO}_{2}$ radical termination reactions rather than $\mathrm{RO}_{2}$ and $\mathrm{HO}_{2}$ radical propagation reactions with NO. Our current isoprene oxidation mechanisms predict $\mathrm{OH}$ concentrations a factor of 10 or more below those observed. The level of discrepancy scales with isoprene concentration suggesting that some processes within isoprene oxidation chemistry are responsible for $\mathrm{OH}$ recycling. Two chamber studies have demonstrated that $\mathrm{OH}$ is produced from two unexpected channels, however, at the time of writing, it has been shown that whilst these channels contribute to $\mathrm{OH}$ formation they do not account for a majority of the discrepancy [53]. Theoretical calculations have suggested further alternative pathways $[54,55]$ and no doubt chamber studies will play important roles in investigating these hypotheses in the near future.

\subsection{1 $\mathrm{RO}_{2}+\mathrm{HO}_{2}$ reactions}

When $\mathrm{R}=$ alkyl radical then the reaction of $\mathrm{RO}_{2}$ with $\mathrm{HO}_{2}$ has been shown to be chain terminating with the formation of a peroxide, $\mathrm{ROOH}$, or alcohol, $\mathrm{ROH}$ :

$$
\begin{gathered}
\mathrm{RO}_{2}+\mathrm{HO}_{2} \rightarrow \mathrm{ROOH}+\mathrm{O}_{2} \\
\mathrm{RO}_{2}+\mathrm{HO}_{2} \rightarrow \mathrm{ROH}+\mathrm{O}_{3} .
\end{gathered}
$$

Peroxide species can be photolysed, regenerating radicals, or react in chain propagation processes, but they are very soluble compounds and uptake into aerosols with subsequent rainout being a major loss process, effectively removing radicals and ozone from the atmosphere. 
Hasson et al. [56] studied the reaction of $\mathrm{CH}_{3} \mathrm{C}(\mathrm{O}) \mathrm{O}_{2}$ (acetylperoxy) radicals with $\mathrm{HO}_{2}$ in the NCAR environmental chamber. Photolysis of molecular chlorine was used as the initial radical source and rapid secondary reactions generated the target radicals:

$$
\begin{gathered}
\mathrm{Cl}+\mathrm{CH}_{3} \mathrm{CHO} \rightarrow \mathrm{CH}_{3} \mathrm{CO}+\mathrm{HCl} \\
\mathrm{CH}_{3} \mathrm{CO}+\mathrm{O}_{2} \rightarrow \mathbf{C H}_{3} \mathbf{C}(\mathbf{O}) \mathbf{O}_{2} \\
\mathrm{Cl}+\mathrm{CH}_{3} \mathrm{OH} \rightarrow \mathrm{CH}_{2} \mathrm{OH}+\mathrm{HCl} \\
\mathrm{CH}_{2} \mathrm{OH}+\mathrm{O}_{2} \rightarrow \mathbf{H O}_{2}+\mathrm{HCHO} .
\end{gathered}
$$

The expected products of the reaction of $\mathrm{CH}_{3} \mathrm{C}(\mathrm{O}) \mathrm{O}_{2}$ and $\mathrm{HO}_{2}$ are peracetic $\left(\mathrm{CH}_{3} \mathrm{C}(\mathrm{O}) \mathrm{OOH}\right)$ and acetic acid $\left(\mathrm{CH}_{3} \mathrm{C}(\mathrm{O}) \mathrm{OH}\right)$ and indeed these were observed using a combination of FTIR and HPLC. However, methyl hydroperoxide, $\mathrm{CH}_{3} \mathrm{OOH}$ was also observed providing indirect evidence for the formation of methyl radicals and a new channel in the $\mathrm{CH}_{3} \mathrm{C}(\mathrm{O}) \mathrm{O}_{2}+\mathrm{HO}_{2}$ reaction:

$$
\begin{gathered}
\mathrm{CH}_{3} \mathrm{C}(\mathrm{O}) \mathrm{O}_{2}+\mathrm{HO}_{2} \rightarrow \mathrm{CH}_{3} \mathrm{C}(\mathrm{O}) \mathrm{OOH}+\mathrm{O}_{2} \\
\mathrm{CH}_{3} \mathrm{C}(\mathrm{O}) \mathrm{O}_{2}+\mathrm{HO}_{2} \rightarrow \mathrm{CH}_{3} \mathrm{C}(\mathrm{O}) \mathrm{OH}+\mathrm{O}_{3} \\
\mathrm{CH}_{3} \mathrm{C}(\mathrm{O}) \mathrm{O}_{2}+\mathrm{HO}_{2} \rightarrow \mathrm{CH}_{3} \mathrm{C}(\mathrm{O}) \mathrm{O}+\mathrm{OH}+\mathrm{O}_{2} .
\end{gathered}
$$

$\mathrm{CH}_{3} \mathrm{C}(\mathrm{O}) \mathrm{O}$ is thermally unstable decomposing to give $\mathrm{CH}_{3}$ (subsequently oxidized to methyl hydroperoxide) and $\mathrm{CO}_{2}$ (observed by FTIR):

$$
\mathrm{CH}_{3} \mathrm{C}(\mathrm{O}) \mathrm{O} \rightarrow \mathrm{CH}_{3}+\mathrm{CO}_{2} .
$$

Simulations of the product yields indicated an $\mathrm{OH}$ branching fraction of $0.40 \pm 0.16$ and more recent studies by Dillon and Crowley [57] have directly observed $\mathrm{OH}$ production in good agreement with the chamber studies.

\subsubsection{Epoxide $+\mathrm{OH}$ formation in the reaction of isoprene oxidation products}

Isoprene, $\mathrm{C}_{5} \mathrm{H}_{8}$, is a diene and the initial step in its oxidation is the addition of $\mathrm{OH}$ to a double bond followed by the rapid addition of $\mathrm{O}_{2}$ to form a hydroxyperoxy radical species. Isomerization of this hydroxyperoxy species has been proposed to lead to $\mathrm{OH}$ and $\mathrm{HO}_{2}$ production [54] [55]. The hydroxyperoxy species can also react with $\mathrm{HO}_{2}$ generating a stable hydroxyperoxide species. However, in contrast to the ROOH species discussed above, as this species is derived from a diene molecule, it still contains a double bond and hence is still reactive with respect to a further $\mathrm{OH}$ addition. Paulot et al. [58] have shown that once this second $\mathrm{OH}$ radical adds, then there is a rearrangement with the formation of an epoxide and the ejection of an $\mathrm{OH}$ radical as shown schematically in Fig. 9.

Paulot et al. studied isoprene oxidation in the Caltech environmental chamber, monitoring products using chemical ionization mass spectrometry. Mass spectrometric measurements were key to their mechanistic studies; $\mathrm{H}_{2} \mathrm{O}_{2}$ was used as the $\mathrm{OH}$ photolytic source and use of $\mathrm{H}_{2}{ }^{18} \mathrm{O}_{2}$ allowed Paulot et al. to unravel the mechanism of this particular reaction. 


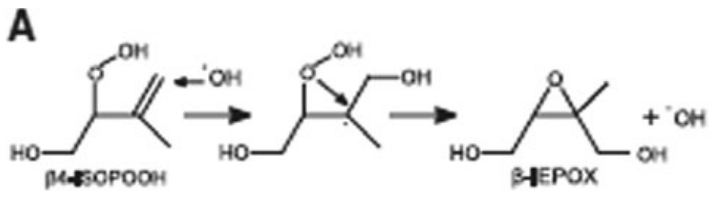

Fig. 9. Reaction mechanism for the formation of an epoxide and the regeneration of $\mathrm{OH}$ [58].

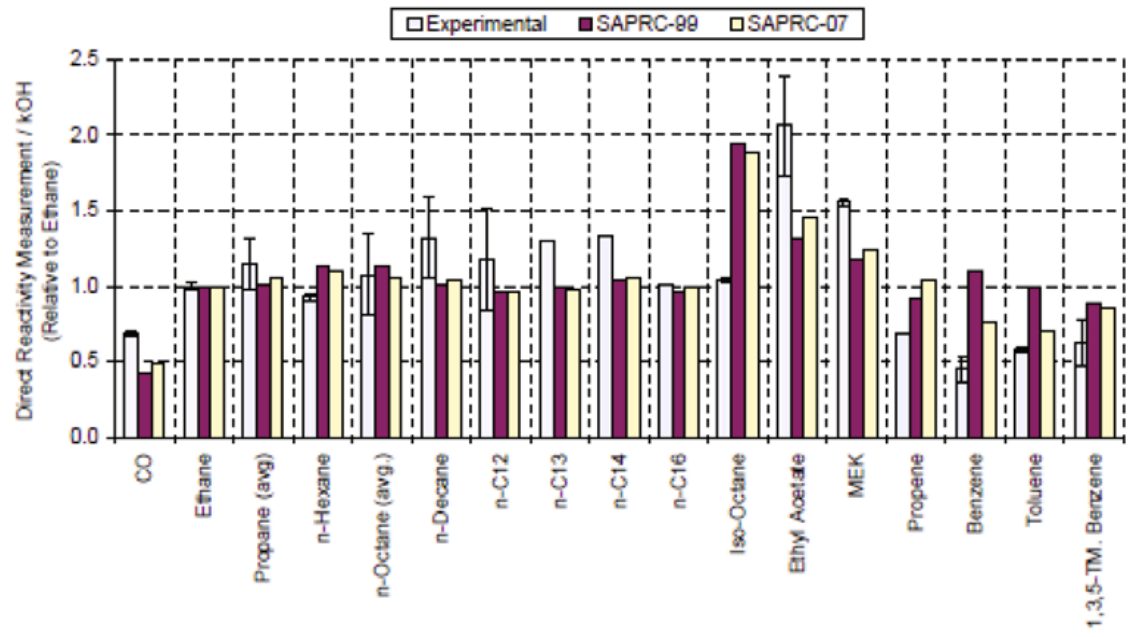

Fig. 10. Model performance of hydrocarbon reactivity in comparison to data obtained from environmental chambers [59].

\subsubsection{The use of chambers to validate complex mechanisms}

The preceding two sub-sections have focused on individual reactions or small components of the overall hydrocarbon oxidation mechanism, however chambers also have an important role in evaluating more complex mechanisms. An example of this can be found in the recent evaluation of the SAPRC07 chemical model by Carter and colleagues at the Air Pollution Research Centre at the University of California, Riverside.

The methods used in such studies are, in many ways, similar to those used in the more detailed studies described above, although mixtures of different hydrocarbons may be used instead of single compounds, and the major emphasis is on comparison with stable products, as most models are designed to reproduce such concentrations, particularly those of legislated compounds such as ozone and nitrogen dioxide, or carcinogens such as benzene.

Figure 10 shows an example of model validation from the study of Carter [59] where simulations from SAPRC99 and the upgraded SAPRC07 chemical models are compared with a comprehensive dataset obtained from chamber studies. SAPRC07 had an improved and updated mechanism for aromatic chemistry as one of its upgrades and Carter comments that the new aromatic oxidation mechanisms do somewhat better than the earlier mechanisms. Aromatic oxidation chemistry is still the subject of much on-going investigation, for example work by Baltaretu et al. [60] on toluene oxidation and the subsequent discussion $[61,62]$.

\subsection{The use of chambers to characterise field instrumentation}

The controlled conditions of an environmental chamber provide an ideal test bed for characterising field instrumentation and examples of studies range from intercomparisons of physical instrumentation such as spectral radiometers [28], through oxygenated VOCs [63], to calibrations of OH radical detection systems $[13,36]$. Many field instruments draw significant sample volumes and hence some studies are limited to the larger chambers such as EUPHORE or SAPHIR. 


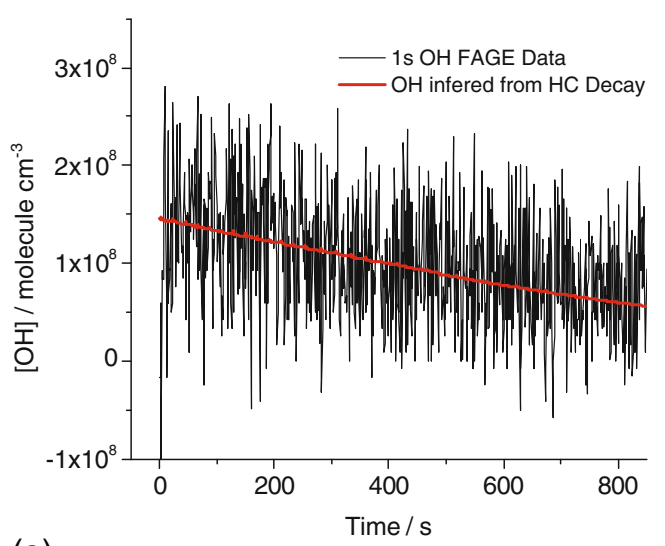

(a)

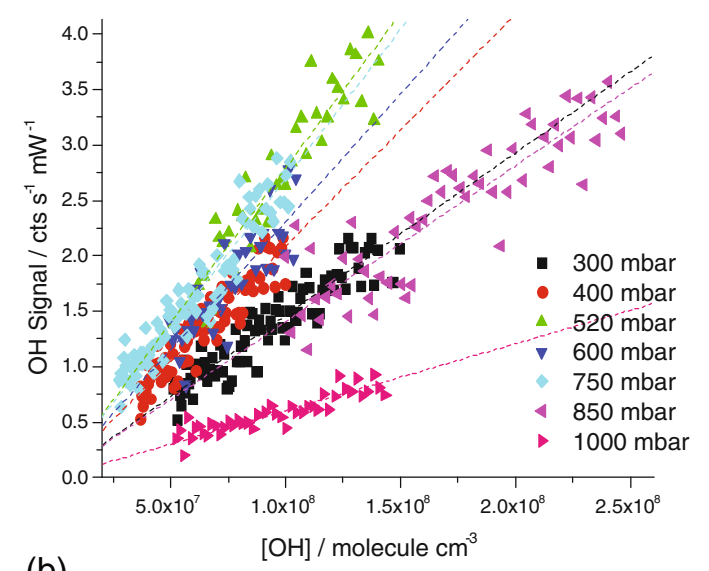

(b)

Fig. 11. (a) Comparison of $\mathrm{OH}$ concentrations calculated from hydrocarbon decays and photolytically calibrated FAGE measurements. (b) Variation of sensitivity as a function of external pressure. The studies were carried out at constant pumping speed so there is a corresponding variation in the internal pressure.

\subsubsection{HOxComp}

HOxComp [13] was a combined field and instrument campaign to compare the performance of several $\mathrm{OH}$ instruments. The initial part of the campaign involved field measurements at the campus of the Forschungszentrum in Julich and involved three laser induced fluorescence instruments and one chemical ionization mass spectrometry (CIMS) instrument based on the design of Eisle and Tanner [64]. Correlations, over the three days of the field trials, between the LIF systems were generally good, although one LIF instrument appeared to measure $\sim 25 \%$ than the other two. The CIMS system recorded values that were between 60 and $75 \%$ of the LIF systems.

The three LIF systems were then transferred to the SAPHIR chamber (the sample volume of the CIMS system was too great to allow sampling from the chamber) and compared with the SAPHIR DOAS OH detection system. The gradients of the regression plots for all combinations of measurements ranged from 0.88-1.10. Systematic investigations of humidity (0-20 mbar), NOx (0.2-9 ppb) and ozone $(0-150 \mathrm{ppb})$ were undertaken with no significant interferences being observed.

\subsubsection{Pressure dependent calibrations of an OH LIF FAGE instrument}

As discussed earlier the FAGE technique is based on fluorescence and therefore requires calibration. Currently most systems use the photolysis at $185 \mathrm{~nm}$ of humidified air, just outside the FAGE inlet to generate known concentrations of $\mathrm{OH}$ and $\mathrm{HO}_{2}$ (Section 4.3.1). However this technique is limited to atmospheric pressure and, as little is known about how the efficiency of FAGE instrumentation varies with pressure, this casts some uncertainty on the results of airborne measures where the external pressure may be changing from 1000-100 mbar. The changing pressure differential between the sampled air and the FAGE chamber (typically 2-5 mbar) may alter the characteristics of the expansion beyond the sample pinhole and hence amount of $\mathrm{OH}$ and $\mathrm{HO}_{2}$ reaching the FAGE fluorescence chambers.

An alternative method of $\mathrm{OH}$ calibration, pioneered by Hard and O'Brien [65], and used more recently by Bloss et al. [66] in the EUPHORE chamber, is to monitor the loss of hydrocarbon, RH, concurrent with $\mathrm{OH}$ measurements. The rate law for the loss of $\mathrm{RH}$ is given by:

$$
-\frac{d[\mathrm{RH}]}{d t}=k_{b i}[\mathrm{OH}][\mathrm{RH}] \text {. }
$$

The hydrocarbon concentration is measured, typically by a GC, as a function of time giving both $\frac{d[\mathrm{RH}]}{d t}$ and $[\mathrm{RH}]$, and $k_{b i}$ is known from separate laboratory measurements or from literature evaluations such 
as those performed by IUPAC [67]. As all the other terms in equation E8 are known or measured, the concentration of $\mathrm{OH}$ at any time can be calculated and used to calibrate the FAGE instrument. Figure 11(a) shows an example where the $[\mathrm{OH}]$ determined from equation E8 is compared to the measured concentration based on a photolytic calibration (section 4.3.1). The agreement is good and the precision of the hydrocarbon calibration can be further improved by the use of multiple hydrocarbons. The photolytic method described above requires the accurate measurement of water vapour which can be challenging.

Figure 11(b) shows examples of calibration plots as a function of pressure in the HIRAC chamber. The sensitivity depends on the internal pressure of the instrument, but the results at different external pressures are within error of those made using the photolytic technique at atmospheric pressure, and with the same internal cell pressure. This would suggest that the nature of the environment experienced by the radicals as they move from the pinhole to the fluorescence chamber (at least $20 \mathrm{~cm}$ ) is unaffected by the pressure differential for this particular FAGE apparatus. As this apparatus is identical to that used by Heard and co-workers for aircraft measurements, it suggests that previous calibrations should be reliable.

\section{Conclusions}

Environmental chambers have a crucial role to play in understanding tropospheric chemistry. In this review we have focused on gas phase chemistry of the Earth's atmosphere, but chambers have equally important roles in investigated heterogeneous processes and are starting to be exploited to simulate the chemistry in other planetary atmospheres [68].

All chambers are characterized by being able to control the starting conditions to focus on either the chemistry of an individual reaction, the performance of a model or to characterise instrumental methods. Within that broad characterization, there are a wide variety of chamber designs, each with their own advantages and disadvantages.

In an introductory review such as this, it is only possible to give a brief flavour of the work that has been carried out using chambers. The literature cited and websites such as EUROCHAMP (http: // wWw . eurochamp . org/) or UC Riverside (http: //cichlid . cert . ucr . edu/about/apl . asp) provide entrance points to a wide range of historical literature and on-going developments.

It is a pleasure to acknowledge the help and support of colleagues and students at the University of Leeds who have contributed so much to construction of the HIRAC chamber at Leeds and carried out the experiments that form the basis of some of this review. These include Profs Pilling and Heard, Drs Goddard, Glowacki, Smith, Hemavibool, Malkin, Blitz, Wada and Ingham, current students Fred Winiberg and Luke Farrugia and the mechanical and electronics workshop staff. Funding has been provided by NERC and the EU EUROCHAMP consortium.

\section{References}

1. S.M. Saunders, M.E. Jenkin, R.G. Derwent, M.J. Pilling, Atmospheric Chemistry and Physics 3, 161 (2003)

2. I. Bey, D.J. Jacob, R.M. Yantosca, J.A. Logan, B.D. Field, A.M. Fiore, Q.B. Li, H.G.Y. Liu, L.J. Mickley, M.G. Schultz, Journal of Geophysical Research-Atmospheres 106 (D19), 23073 (2001)

3. P.W. Seakins, Annual Reports on the Progress of Chemistry, Section C: Physical Chemistry 103 (2007)

4. J.J. Orlando, G.S. Tyndall, T.J. Wallington, Chemical Reviews 103 (12), 4657 (2003)

5. D.E. Heard and M.J. Pilling, Chemical Reviews 103, 5163 (2003)

6. B. Bohn, F. Rohrer, T. Brauers, A. Wahner, Atmospheric Chemistry and Physics 5, 493 (2005)

7. Y. Iinuma, O. Boge, T. Gnauk, and H. Herrmann, Atmospheric Environment 38 (5), 761 (2004)

8. D. Paulsen, J. Dommen, M. Kalberer, A.S.H. Prevot, R. Richter, M. Sax, M. Steinbacher, E. Weingartner, U. Baltensperger, Environmental Science \& Technology 39 (8), 2668 (2005)

9. W.P.L. Carter, D.R. Cocker, D.R. Fitz, I.L. Malkina, K. Bumiller, C.G. Sauer, J.T. Pisano, C. Bufalino, C. Song, Atmospheric Environment 39 (40), 7768 (2005) 
10. J.D. Surratt, A.W.H. Chan, N.C. Eddingsaas, M.N. Chan, C.L. Loza, A.J. Kwan, S.P. Hersey, R.C. Flagan, P.O. Wennberg, J.H. Seinfeld, Proceedings of the National Academy of Sciences of the United States of America 107 (15), 6640 (2010)

11. M. Hallquist, J.C. Wenger, U. Baltensperger, Y. Rudich, D. Simpson, M. Claeys, J. Dommen, N.M. Donahue, C. George, A.H. Goldstein, J.F. Hamilton, H. Herrmann, T. Hoffmann, Y. Iinuma, M. Jang, M.E. Jenkin, J.L. Jimenez, A. Kiendler-Scharr, W. Maenhaut, G. McFiggans, T.F. Mentel, A. Monod, A.S.H. Prevot, J.H. Seinfeld, J.D. Surratt, R. Szmigielski, J. Wildt, Atmospheric Chemistry and Physics 9 (14), 5155 (2009)

12. F. Rohrer, B. Bohn, T. Brauers, D. Bruning, F.J. Johnen, A. Wahner, and J. Kleffmann, Atmospheric Chemistry and Physics 5, 2189 (2005)

13. E. Schlosser, T. Brauers, H.P. Dorn, H. Fuchs, R. Haseler, A. Hofzumahaus, F. Holland, A. Wahner, Y. Kanaya, Y. Kajii, K. Miyamoto, S. Nishida, K. Watanabe, A. Yoshino, D. Kubistin, M. Martinez, M. Rudolf, H. Harder, H. Berresheim, T. Elste, C. Plass-Dulmer, G. Stange, U. Schurath, Atmospheric Chemistry and Physics 9 (20), 7923 (2009)

14. J.Z. Yu, H.E. Jeffries, K.G. Sexton, Atmospheric Environment 31 (15), 2261 (1997)

15. G.D. Hess, F. Carnovale, M.E. Cope, G.M. Johnson, Atmospheric Environment Part a-General Topics $26(4), 625$ (1992)

16. H.P. Dorn, U. Brandenburger, T. Brauers, H. Hausmann, Journal of the Atmospheric Sciences 52 (19), 3373 (1995)

17. P. Wiesen and http: //www . eurochamp.org/, (2010)

18. K.E. Leather, M.R. McGillen, C.J. Percival, Physical Chemistry Chemical Physics 12 (12), 2935 (2010)

19. R.E. Shetter, J.A. Davidson, C.A. Cantrell, J.G. Calvert, Review of Scientific Instruments 58 (8), 1427 (1987)

20. D.R. Glowacki, A. Goddard, K. Hemavibool, T.L. Malkin, R. Commane, F. Anderson, W.J. Bloss, D.E. Heard, T. Ingham, M.J. Pilling, P.W. Seakins, Atmospheric Chemistry and Physics 7, 5371 (2007)

21. T.L. Malkin, University of Leeds, 2010

22. I. Barnes, K.H. Becker, N. Mihalopoulos, Journal of Atmospheric Chemistry 18 (3), 267 (1994)

23. K.H. Becker, in Environmental Simulation Chambers: Application to Atmospheric Chemical Processes, edited by I. Barnes and K.J. Rudzinski (Springer, Dordrecht, 2006), Vol. 62, pp. 1

24. H. Akimoto, M. Hoshino, G. Inoue, F. Sakamaki, N. Washida, M. Okuda, Environmental Science \& Technology 13 (4), 471 (1979)

25. L.P. Thuner, P. Bardini, G.J. Rea, J.C. Wenger, Journal of Physical Chemistry A 108 (50), 11019 (2004)

26. R. Simonaitis, J.F. Meagher, E.M. Bailey, Atmospheric Environment 31 (1), 27 (1997)

27. M.E. Jenkin, M.D. Hurley, T.J. Wallington, Physical Chemistry Chemical Physics 10 (29), 4274 (2008)

28. B. Bohn, G.K. Corlett, M. Gillmann, S. Sanghavi, G. Stange, E. Tensing, M. Vrekoussis, W.J. Bloss, L.J. Clapp, M. Kortner, H.P. Dorn, P. S. Monks, U. Platt, C. Plass-Dulmer, N. Mihalopoulos, D.E. Heard, K.C. Clemitshaw, F.X. Meixner, A.S.H. Prevot, R. Schmitt, Atmospheric Chemistry and Physics 8 (17), 5373 (2008)

29. J. White, Journal of the Optical Society of America 32, 285 (1942)

30. S.M. Chernin, Journal of Modern Optics 48, 619 (2001)

31. D.R. Glowacki, A. Goddard, P.W. Seakins, Applied Optics 46 (32), 7872 (2007)

32. R. Volkamer, U. Platt, K. Wirtz, Journal of Physical Chemistry A 105 (33), 7865 (2001)

33. L.G. Huey, Mass Spectrometry Reviews 26 (2), 166 (2007)

34. R.S. Blake, P.S. Monks, A.M. Ellis, Chemical Reviews 109 (3), 861 (2009)

35. A. Lee, A.H. Goldstein, M.D. Keywood, S. Gao, V. Varutbangkul, R. Bahreini, N.L. Ng, R.C. Flagan, J.H. Seinfeld, Journal of Geophysical Research-Atmospheres 111 (D7), 18 (2006)

36. E. Schlosser, B. Bohn, T. Brauers, H.P. Dorn, H. Fuchs, R. Haseler, A. Hofzumahaus, F. Holland, F. Rohrer, L.O. Rupp, M. Siese, R. Tillmann, A. Wahner, Journal of Atmospheric Chemistry 56 (2), 187 (2007) 
37. T.M. Hard, R.J. Obrien, C.Y. Chan, A.A. Mehrabzadeh, Environmental Science \& Technology 18 (10), 768 (1984)

38. C. CamyPeyret, B. Bergqvist, B. Galle, M. Carleer, C. Clerbaux, R. Colin, C. Fayt, F. Goutail, M. NunesPinharanda, J.P. Pommereau, M. Hausmann, U. Platt, I. Pundt, T. Rudolph, C. Hermans, P.C. Simon, A.C. Vandaele, J.M.C. Plane, N. Smith, Journal of Atmospheric Chemistry 23 (1), $51(1996)$

39. A. Okeefe and D.A.G. Deacon, Review of Scientific Instruments 59 (12), 2544 (1988)

40. M.D. Wheeler, S.M. Newman, A.J. Orr-Ewing, M.N.R. Ashfold, Journal of the Chemical SocietyFaraday Transactions 94 (3), 337 (1998)

41. S.S. Brown, Chemical Reviews 103 (12), 5219 (2003)

42. H. Fuchs, S.M. Ball, B. Bohn, T. Brauers, R.C. Cohen, H.P. Dorn, W.P. Dube, J.L. Fry, R. Haseler, U. Heitmann, R.L. Jones, J. Kleffmann, T.F. Mentel, P. Musgen, F. Rohrer, A.W. Rollins, A.A. Ruth, A. Kiendler-Scharr, E. Schlosser, A.J.L. Shillings, R. Tillmann, R.M. Varma, D.S. Venables, G.V. Tapia, A. Wahner, R. Wegener, P.J. Wooldridge, S. S. Brown, Atmospheric Measurement Techniques 3 (1), 21 (2010)

43. C.A. Cantrell, D.H. Stedman, G.J. Wendel, Analytical Chemistry 56 (8), 1496 (1984)

44. E. Iwasaki, H. Chiba, T. Nakayama, Y. Matsumi, T.J. Wallington, Chemical Physics Letters 494 (4-6), 174 (2010)

45. T.J. Wallington, J.M. Andino, I.M. Lorkovic, E.W. Kaiser, G. Marston, Journal of Physical Chemistry 94 (9), 3644 (1990)

46. D. Johnson, G. Marston, Chemical Society Reviews 37 (4), 699 (2008)

47. P. Neeb, G.K. Moortgat, Journal of Physical Chemistry A 103 (45), 9003 (1999)

48. M. Karl, T. Brauers, H.P. Dorn, F. Holland, M. Komenda, D. Poppe, F. Rohrer, L. Rupp, A. Schaub, A. Wahner, Geophysical Research Letters 31 (5), 4 (2004)

49. T.L. Malkin, A. Goddard, D.E. Heard, P.W. Seakins, Atmospheric Chemistry and Physics 10 (3), $1441(2010)$

50. S.E. Paulson, M. Chung, A.D. Sen, G. Orzechowska, Journal of Geophysical ResearchAtmospheres 103 (D19), 25533 (1998)

51. J. Lelieveld, T.M. Butler, J.N. Crowley, T.J. Dillon, H. Fischer, L. Ganzeveld, H. Harder, M.G. Lawrence, M. Martinez, D. Taraborrelli, J. Williams, Nature 452, 737 (2008)

52. C.N. Hewitt, J.D. Lee, A.R. MacKenzie, M.P. Barkley, N. Carslaw, G.D. Carver, N.A. Chappell, H. Coe, C. Collier, R. Commane, F. Davies, B. Davison, P. Di Carlo, C.F. Di Marco, J.R. Dorsey, P.M. Edwards, M.J. Evans, D. Fowler, K.L. Furneaux, M. Gallagher, A. Guenther, D.E. Heard, C. Helfter, J. Hopkins, T. Ingham, M. Irwin, C. Jones, A. Karunaharan, B. Langford, A.C. Lewis, S.F. Lim, S.M. MacDonald, A.S. Mahajan, S. Malpass, G. McFiggans, G. Mills, P. Misztal, S. Moller, P.S. Monks, E. Nemitz, V. Nicolas-Perea, H. Oetjen, D.E. Oram, P.I. Palmer, G.J. Phillips, R. Pike, J.M.C. Plane, T. Pugh, J.A. Pyle, C.E. Reeves, N.H. Robinson, D. Stewart, D. Stone, L.K. Whalley, X. Yin, Atmospheric Chemistry and Physics 10 (1), 169 (2010)

53. A.T. Archibald, M.C. Cooke, S.R. Utembe, D.E. Shallcross, R.G. Derwent, M.E. Jenkin, Atmospheric Chemistry and Physics Discussions 10, 5863 (2010)

54. G. Da Silva, C. Graham, Z.F. Wang, Environmental Science \& Technology 44 (1), 250 (2010)

55. J. Peeters, T.L. Nguyen, L. Vereecken, Physical Chemistry Chemical Physicis 11, 5935 (2009)

56. A.S. Hasson, G.S. Tyndall, J.J. Orlando, Journal of Physical Chemistry A 108, 5979 (2004)

57. T.J. Dillon, J.N. Crowley, Atmospheric Chemistry and Physics 8, 4877 (2008)

58. R. Paulot, J.D. Crounse, H.G. Kjaergaard, A. Kurten, J.M.St. Clair, J.H. Seinfeld, P.O. Wennberg, Science (Washington, D. C., 1883-) 325, 730 (2009)

59. W.P.L. Carter, Report to the California Air Resources Board Center for Environmenta Research and Technology, University of California, Riverside, www.engr.ucr.edu/ carter/SAPRC/ saprc07.pdf (2010)

60. C.O. Baltaretu, E.I. Lichtman, A.B. Hadler, M.J. Elrod, Journal of Physical Chemistry A 113 (1), 221 (2009)

61. M.E. Jenkin, D.R. Glowacki, A.R. Rickard, M. J. Pilling, Journal of Physical Chemistry A 113 (28), 8136 (2009) 
62. C.O. Baltaretu, E.I. Lichtman, A.B. Hadler, M.J. Elrod, Journal of Physical Chemistry A 113 (28), 8139 (2009)

63. E.C. Apel, T. Brauers, R. Koppmann, B. Bandowe, J. Bossmeyer, C. Holzke, R. Tillmann, A. Wahner, R. Wegener, A. Brunner, M. Jocher, T. Ruuskanen, C. Spirig, D. Steigner, R. Steinbrecher, E.G. Alvarez, K. Muller, J.P. Burrows, G. Schade, S.J. Solomon, A. Ladstatter-Weissenmayer, P. Simmonds, D. Young, J.R. Hopkins, A.C. Lewis, G. Legreid, S. Reimann, A. Hansel, A. Wisthaler, R.S. Blake, A.M. Ellis, P.S. Monks, K.P. Wyche, Journal of Geophysical Research-Atmospheres 113 (D20), 24 (2008)

64. F.L. Eisele, D.J. Tanner, Journal of Geophysical Research-Atmospheres 96 (D5), 9295 (1991)

65. T.M. Hard, L.A. George, R.J. Obrien, Journal of the Atmospheric Sciences 52 (19), 3354 (1995)

66. W.J. Bloss, J.D. Lee, C. Bloss, D.E. Heard, M.J. Pilling, K. Wirtz, M. Martin-Reviejo, M. Siese, Atmospheric Chemistry and Physics 4, 571 (2004)

67. R. Atkinson, D.L. Baulch, R.A. Cox, J.N. Crowley, R.F. Hampson, R.G. Hynes, M.E. Jenkin, M.J. Rossi, J. Troe, Atmospheric Chemistry and Physics 4, 1461 (2004)

68. V. Vuitton, J.F. Doussin, Y. Benilan, F. Raulin, M.C. Gazeau, Icarus 185 (1), 287 (2006) 